\title{
Efficiency and distribution effects of a revenue-neutral income tax reform
}

\author{
Burkhard Heer ${ }^{\mathrm{a}, \mathrm{b}, *}$, Mark Trede ${ }^{\mathrm{c}}$ \\ ${ }^{a}$ Department of Economics, University of Bamberg, Feldkirchenstrasse 21, 96045 Bamberg, Germany \\ ${ }^{\mathrm{b}}$ CESifo, Munich, Germany \\ ${ }^{\mathrm{c}}$ Department of Econometrics and Economic Statistics, University of Munster, \\ Am Stadtgraben 9, 48143 Munster, Germany
}

\begin{abstract}
We study the quantitative effects of two revenue-neutral income tax reform proposals, (i) a flat-rate tax and (ii) a consumption tax, in a general equilibrium model with elastic labor supply and progressive income taxation. Households are heterogeneous with regard to their productivity and their assets. The model is calibrated with regard to the German economy in 1996. Importantly, the endogenous labor income distribution as computed from our model is equal to the empirical labor income distribution in Germany. As our first main result, both reform proposals are shown to have only negligible effects on the labor income distribution. Second, both tax reform proposals result in a moderate increase of aggregate employment and a strong increase of aggregate savings. And third, both reform proposals imply significant steady-state welfare gains equivalent to a rise of total consumption of $3.6 \%$ and $8.2 \%$, respectively.
\end{abstract}

JEL classification: D33; E62; H23; H24

Keywords: Income taxation; Consumption taxation; Income distribution; Flat-rate tax

\footnotetext{
${ }^{*}$ Corresponding author. Address: Department of Economics, University of Bamberg, Feldkirchenstrasse 21, 96052 Bamberg, Germany.

E-mail addresses: burkhard.heer@sowi.uni-bamberg.de (B. Heer), mark.trede@uni-muenster.de (M. Trede).
} 


\section{Introduction}

This paper studies the efficiency and distribution effects of two tax reform proposals which have been discussed prominently in recent German policy debates: (1) a flat-rate income tax reform and (2) a switch from the income tax to a consumption tax. In Germany, the income tax is progressive even though the recent tax reforms in the years 1986, 1988, 1990, and 1998 have helped to reduce marginal tax rates. ${ }^{1}$ The effects of a progressive income tax on efficiency and welfare are not straightforward, however, and critically depend on the labor market structure. In competitive labor markets, which will be the focus of the present paper, progressive income taxation reduces the labor supply of the very productive worker on the one hand and the savings of the wealth-rich on the other hand which will result in smaller aggregate labor supply, capital accumulation, and income. ${ }^{2}$ A flat-rate tax, however, increases income inequality and, hence, decreases welfare. The net effect on welfare can only be evaluated numerically. Our second focus is the analysis of a shift from income taxation to consumption taxation. Contrary to the income tax, a consumption tax is neutral with regard to the intertemporal allocation as it does not tax interest income.

We develop an intertemporal general equilibrium model which is calibrated with regard to the characteristics of the German economy. In particular, we closely represent the present German personal income tax schedule in our benchmark calibration. In our model of income inequality and income mobility, agents face uninsurable idiosyncratic productivity shocks and, between periods, individual productivity may change. As a consequence, individual labor income also changes. Our general equilibrium model is able to account for both the observed heterogeneity in wage rates and the observed labor income mobility. In addition, we model the household's labor supply decision. As a consequence, the labor income distribution is endogenous. As one major implication of our modelling framework, we are able replicate the German labor income distribution quite closely.

In our model, labor adjusts only along the intensive margin as agents change their supply of working hours. Recent computable general equilibrium studies with heterogeneous-agent economies have also emphasized the effects of public policy on aggregate employment. E.g., Heer (2003) shows in a model of search unemployment that an increase of unemployment benefits results in a rise of the unemployment rate. We do not analyze the adjustment of labor along the extensive margin in our model, which we consider to be a fruitful area for further research, but rather take the unemployment rate as given. However, contrary to similar studies of the US economy

\footnotetext{
${ }^{1}$ As a second major impact, the recent tax reforms have also relieved the tax burden on the low-income families.

${ }^{2}$ In the presence of non-Walrasian labor markets, however, a progressive income tax does not necessarily increase employment. Assume that wages result from Nash bargaining, that union's utility depends on both employment and post-tax wage, and that firms have the right to manage. For a constant average income tax, a decrease of the marginal tax rate induces a substitution effect towards higher employment as a unit decrease in post-tax wages results in a higher employment gain. See, e.g., Lockwood and Manning (1993) for both theoretical and empirical evidence.
} 
such as Castañeda et al. (1998) or Ventura (1999), we consider the risk of unemployment in our model. Agents face an exogenous probability both to become and to remain unemployed. During unemployment, agents receive unemployment benefits and loose their skills.

We will only consider revenue-neutral tax reforms and keep government consumption and unemployment compensation constant. In our first tax experiment, we compute the flat-rate income tax rate which implies the same income tax revenues as in our benchmark economy. Welfare is measured by the average life-time utility of all households in the economy. As our first main result, we show that a flat-rate tax increases aggregate employment and savings as well as average welfare. In our second tax experiment, we set the income taxes to zero and compute the consumption tax rate which implies the same tax revenues as in the benchmark model with the present German tax structure. As our second main result, we find that an increase of the consumption tax which is offset by a reduction of the income tax rate mainly boosts savings, but also increases aggregate employment. The distribution of wealth becomes much more unequal. Again, aggregate welfare increases.

The organisation of the paper is as follows. Section 2 introduces the model. In Section 3, the model is calibrated with regard to characteristics of the German economy. In Section 4, our numerical results are presented. Section 5 concludes. Appendices $\mathrm{A}, \mathrm{B}, \mathrm{C}, \mathrm{D}$ provide a description of the stationary equilibrium concept and the computational methods.

\section{The model}

The model is based on the stochastic neoclassical growth model with elastic labor supply and idiosyncratic risk, augmented by a government sector. Agents are subject to idiosyncratic productivity and employment shocks which they are not able to insure against; however, there is no aggregate uncertainty in the economy. Three different sectors are depicted: households, firms, and the government. Households maximize discounted life-time utility with regard to their intertemporal consumption and labor supply. Firms maximize their profits and produce with constant returns to scale using labor and capital as inputs. The government taxes income and spends the revenues on government consumption and unemployment compensation.

\subsection{Households}

Households are of measure one and infinitely lived. Households are heterogeneous with regard to their employment status, their productivity $\epsilon^{j}$, and their wealth $k^{j}, j \in[0,1]{ }^{3}$ We assume productivity $\epsilon$ to take a value from the finite set $\mathscr{E}=\left\{\epsilon^{1}, \epsilon^{2}, \ldots, \epsilon^{n \epsilon}\right\}$, where $\epsilon^{1}=0$ describes the state of unemployment. We assume

\footnotetext{
${ }^{3}$ As we only consider one type of asset, we will refer to $k$ as capital, wealth, and asset interchangeably.
} 
that productivity follows a first order finite state Markov chain with conditional transition probabilities given by

$$
\pi\left(\epsilon^{\prime} \mid \epsilon\right)=\operatorname{Pr}\left\{\epsilon_{t+1}=\epsilon^{\prime} \mid \epsilon_{t}=\epsilon\right\},
$$

where $\epsilon, \epsilon^{\prime} \in \mathscr{E}$. Although the dynamics of productivity may be modelled slightly better by a second order Markov chain (Shorrocks, 1976) the improvement in accuracy is rather small and does not justify the considerable increase in the model's complexity.

Household $j$, which is characterized by productivity $\epsilon_{t}^{j}$ and wealth $k_{t}^{j}$ in period $t$, maximizes his intertemporal utility with regard to consumption $c_{t}^{j}$ and labor supply $n_{t}^{j}$ :

$$
E_{0} \sum_{t=0}^{\infty} \beta^{t} u\left(c_{t}^{j}, 1-n_{t}^{j}\right),
$$

where $\beta<1$ is a discount factor and expectations are conditioned on the information set of the household at time 0 . Instantaneous utility $u\left(c_{t}, 1-n_{t}\right)$ is assumed to be additively separable in the utility from consumption and the utility from leisure as given by ${ }^{4}$

$$
u\left(c_{t}, 1-n_{t}\right)=\frac{c_{t}^{1-\sigma}}{1-\sigma}+\gamma_{0} \frac{\left(1-n_{t}\right)^{1-\gamma_{1}}}{1-\gamma_{1}} .
$$

Agents are not allowed to borrow, $k^{j} \geqslant 0$. In addition, the household faces a budget constraint. He receives income from labor $n_{t}$ and capital $k_{t}$ which he spends on consumption $c_{t}$ and next-period wealth $k_{t+1}$ :

$$
k_{t+1}^{j}=(1+r) k_{t}^{j}+w_{t} n_{t}^{j} \epsilon_{t}^{j}-\left(1+\tau_{\mathrm{c}}\right) c_{t}^{j}-\tau\left(y_{t}^{j}\right)+1_{\epsilon=\epsilon^{1}} b_{t},
$$

where $r_{t}, w_{t}, \tau_{\mathrm{c}}$, and $\tau(y)$ denote the interest rate, the wage rate, the consumption tax rate, and the taxes on income $y$, respectively. $1_{\epsilon=\epsilon^{1}}$ is an index function which takes the value one if the household is unemployed $\left(\epsilon=\epsilon^{1}\right)$ and zero otherwise. If the agent is unemployed, he receives unemployment compensation $b_{t}$. Taxable income is composed of interest income and labor income:

$$
y_{t}^{j}=y_{t}^{j}\left(\epsilon_{t}^{j}, k_{t}^{j}\right)=r k_{t}^{j}+w_{t} n_{t}^{j} \epsilon_{t}^{j} .
$$

\subsection{Production}

Firms are owned by the households and maximize profits with respect to their labor and capital demand. Production $F\left(K_{t}, N_{t}\right)$ is characterized by constant returns to scale using capital $K_{t}$ and labor $N_{t}$ as inputs:

\footnotetext{
${ }^{4}$ Our choice of the functional form for utility follows Castañeda et al. (1998). Most quantitative studies of general equilibrium model specify a Cobb-Douglas functional form of utility. In this case, however, the elasticity of individual labor supply with regard to wealth is larger than for the utility function (3) and, consequently, the distribution of both labor income and wealth are even more homogeneous than for our choice of the utility function (3).
} 


$$
F\left(K_{t}, N_{t}\right)=K_{t}^{\alpha} N_{t}^{1-\alpha}
$$

In a market equilibrium, factors are compensated according to their marginal products and profits are zero:

$$
\begin{aligned}
& r_{t}=\alpha\left(\frac{N_{t}}{K_{t}}\right)^{1-\alpha}-\delta, \\
& w_{t}=(1-\alpha)\left(\frac{K_{t}}{N_{t}}\right)^{\alpha},
\end{aligned}
$$

where $\delta$ denotes the depreciation rate of capital.

\subsection{Government}

Government expenditures consist of government consumption $G_{t}$ and unemployment compensation $B_{t} .{ }^{5}$ In our benchmark case, government expenditures are financed by an income tax and a consumption tax. The latter is proportional to consumption. The income tax structure is chosen to match the current income tax structure in Germany most closely. In particular, the income tax is comprised of $M$ different tax brackets $y_{t} \in\left(Y_{m-1}, Y_{m}\right]$ with corresponding marginal tax rates $\tau_{m}$, $m=1,2, \ldots, M$. An agent with income $y_{t} \in\left(Y_{m-1}, Y_{m}\right]$ pays the amount of taxes (tax policy $i)$

$$
\tau\left(y_{t}\right)=\tau_{1}\left(Y_{1}-Y_{0}\right)+\tau_{2}\left(Y_{2}-Y_{1}\right)+\cdots+\tau_{m}\left(y_{t}-Y_{m-1}\right) .
$$

The marginal tax rates $\tau_{i}$ and the thresholds $Y_{i}$ will be adjusted for the current German income tax structure. In particular, the German income tax structure is progressive with $\tau_{i}<\tau_{i+1}$ for all $i=1, \ldots, M-1$.

We will compare the employment, distribution, and welfare effects of the current tax structure with the effects of two other tax structures, (i) a flat-rate income tax structure and (ii) a consumption tax. In the former case, taxes are a proportional function of income (tax policy ii):

$$
\tau\left(y_{t}\right)=\tau_{y} y_{t} .
$$

In the second case, a consumption tax $\tau_{\mathrm{c}} c_{t}$ is imposed on individuals, while $\tau\left(y_{t}\right)=0$ (tax policy iii). The two alternative tax policy regimes are calibrated in order to yield the same stationary tax revenues $T_{t}$ as the current income tax structure.

The government budget is assumed to balance in every period so that government expenditures are financed by tax revenues $T_{t}$ in every period $t$ :

$$
G_{t}+B_{t}=T_{t} .
$$

We will concentrate on the analysis of a stationary equilibrium where equilibrium prices are constant and the distribution of both income and wealth is invariant. A definition of the equilibrium concept used in this paper is provided in Appendix A.

\footnotetext{
${ }^{5}$ Government consumption does not have any effect on either utility nor production. In this paper, we hold government consumption fixed and only analyze revenue-neutral tax reforms.
} 


\section{Calibration}

In order to compute the quantitative effects of the different fiscal policy regimes on output, employment, distribution, and welfare, the model has to be calibrated. The model parameters are chosen with respect to the characteristics of the German economy during 1995-1996. Model periods correspond to years. Data are mainly from the quarterly national account statistics of the German Institute for Economic Research (DIW), Berlin. The annual data on the unemployment rate is taken from the yearbooks of the German Statistical Office (Statistisches Bundesamt). Data on the wage and income distribution is taken from the Socio-Economic Panel for Germany (GSOEP). The parameters $\sigma, \beta, \alpha, \delta, \gamma_{g}, b$ are chosen from estimates, while the utility parameters $\gamma_{0}$ and $\gamma_{1}$ on the one hand and the productivities $\epsilon^{j}$ together with the transition probabilities $\pi\left(\epsilon^{\prime} \mid \epsilon\right)$ on the other hand are chosen jointly to replicate certain statistics from the labor market. All other parameters of the model, e.g. the consumption tax rate $\tau_{\mathrm{c}}$, are computed endogenously from the model.

\subsection{Utility}

For the utility function parameters, we chose the usual discount rate of $\beta=0.96$ and set $\sigma$ equal to $2 .{ }^{6}$ The parameters $\gamma_{0}$ and $\gamma_{1}$ are chosen in order to imply (i) an average working time of approximately $1 / 3$ and (ii) a coefficient of variation of workers' labor supply equal to the empirical value. Using data from the Socio-Economic Panel, we estimated a coefficient of variation of 0.385 during 1995-1996. For our benchmark case with the utility parameters $\gamma_{0}=0.13$ and $\gamma_{1}=10$, the average labor supply of the workers is equal to 0.320 , while the coefficient of variation amounts to 0.363 . Our calibration is summarized in Table 1 .

\subsection{Productivity}

The productivities $\epsilon \in \mathscr{E}=\left\{\epsilon^{1}, \ldots, \epsilon^{n \epsilon}\right\}$ are chosen to replicate the discretized distribution of hourly wage rates which according to (4) are proportional to productivity. The number of productivities is set equal to $n \epsilon=5 . \epsilon^{1}$ characterizes the state of unemployment and is set equal to zero. The productivities $\left\{\epsilon^{2}, \epsilon^{3}, \epsilon^{4}, \epsilon^{5}\right\}$ are estimated from the empirical distribution of hourly wages in Germany (1995). The productivity $\epsilon^{i}$ corresponds to the average hourly wage rate of earners in the $(i-1)$ th quartile. Normalizing the average of the four non-zero productivities to unity we arrive at

$$
\left\{\epsilon^{2}, \epsilon^{3}, \epsilon^{4}, \epsilon^{5}\right\}=\{0.4476,0.7851,1.0544,1.7129\} .
$$

The transition probability into and out of unemployment, $\pi\left(\epsilon^{\prime}=0 \mid \epsilon>0\right)$ and $\pi\left(\epsilon^{\prime}>0 \mid \epsilon=0\right)$ where $\epsilon^{\prime}$ represents next period's productivity, are chosen in order

\footnotetext{
${ }^{6}$ Empirical estimates of the intertemporal elasticity of substitution $1 / \sigma$ vary considerably. We perform a sensitivity analysis of our numerical results with regard to the parameter in Appendix C. All our qualitative results are robust with regard to the choice $\sigma \in[1,4]$.
} 
Table 1

Calibration of parameter values for benchmark case

\begin{tabular}{lll}
\hline Description & Function & Parameter \\
\hline Utility function & $u_{t}=\left(c_{t}^{1-\sigma} /(1-\sigma)\right)+\gamma_{0}\left((1-n)^{1-\gamma_{1}} / 1-\gamma_{1}\right)$ & $\sigma=2, \gamma_{0}=0.13$, \\
& & $\gamma_{1}=10$ \\
Discount factor & $\beta$ & $\beta=0.96$ \\
Production function & $F(K, N)=K^{\alpha} N^{1-\alpha}$ & $\alpha=0.36$ \\
Depreciation & $\delta$ & $\delta=0.04$ \\
Government consumption & $\bar{G}=\gamma_{\mathrm{g}} F(\bar{K}, N)$ & $\gamma_{\mathrm{g}}=19.6 \%$ \\
Unemployment compensation & $b$ & $b=0.52 \epsilon^{2} w \bar{n}^{2}$ \\
\hline
\end{tabular}

to imply an average unemployment rate of $10.95 \%$ and an average duration of unemployment equal to slightly more than one year (we assume that the average transition takes place in the middle of the year). Further, we assume that the probability to loose one's job does not depend on the individual productivity. During unemployment, the worker's human capital depreciates or, equivalenty, his productivity decreases. We assume that the worker can only reach productivity $\epsilon^{2}$ after unemployment and set $\pi\left(\epsilon^{\prime}=\epsilon^{2} \mid \epsilon=0\right)=1-\pi\left(\epsilon^{\prime}=0 \mid \epsilon=0\right)$ and $\pi\left(\epsilon^{\prime}>\epsilon^{2} \mid \epsilon=0\right)=0 .{ }^{7}$ The remaining $(n \epsilon-1)^{2}=16$ transition probabilities are calibrated such that (i) each row in the Markov transition matrix sums to one, (ii) the model economy matches the observed quartile transition probabilities of the hourly wage rate from 1995 to 1996 as given by the GSOEP data. Our approach to the issue of mobility is hence markedly different from Castañeda et al. (1998) who calibrate the transition matrix is order to replicate the US earnings and wealth distribution as closely as possible. As a consequence, the diagonal elements of the transition matrix calibrated by Castañeda et al. (1998) are far larger than the empirical counterparts.

Our transition matrix is given by

$$
\pi\left(\epsilon^{\prime} \mid \epsilon\right)=\left(\begin{array}{lllll}
0.3500 & 0.6500 & 0.0000 & 0.0000 & 0.0000 \\
0.0800 & 0.6751 & 0.1702 & 0.0364 & 0.0383 \\
0.0800 & 0.1651 & 0.5162 & 0.2003 & 0.0384 \\
0.0800 & 0.0422 & 0.1995 & 0.5224 & 0.1559 \\
0.0800 & 0.0371 & 0.0345 & 0.1606 & 0.6879
\end{array}\right) \text {. }
$$

\subsection{Tax function}

The benchmark case is calibrated in order to approximate the features of the income tax code in Germany. For this reason, tax income thresholds $Y_{i}$,

\footnotetext{
${ }^{7}$ Alternatively, we could have assumed that the worker's productivity does not decrease during unemployment. In this case, however, we had to introduce an additional state variable into the model which makes the computation and calibration even more cumbersome.
} 
Table 2

Tax code

\begin{tabular}{ll}
\hline Taxable income relative to average income & Marginal income tax rate $\tau_{\mathrm{i}}(\%)$ \\
\hline$[0,0.200]$ & 0 \\
] $0.200,0.650]$ & 15.0 \\
] $0.650,0.737]$ & 17.6 \\
] $0.737,0.823]$ & 18.9 \\
] $0.823,0.910]$ & 19.3 \\
] $0.910,0.997]$ & 20.2 \\
] $0.997,1.083]$ & 23.0 \\
] $1.083,1.170]$ & 28.2 \\
] $1.170,1.256]$ & 33.4 \\
$>1.256$ & 34.6 \\
\hline
\end{tabular}

$i=0, \ldots, M-1$, relative to the average income are chosen to match the values of their empirical counterparts. The marginal tax rates $\tau_{i}, i=1, \ldots, M$, in the income brackets are taken from Sieg (2000). ${ }^{8}$ Sieg provides non-parametric estimates for the marginal tax rates in Germany using data from the GSOEP. The marginal tax rates are estimated for the married household with two children with bootstrapping methods. For the readers' convenience we replicate his estimates in Table 2. We have set the marginal income tax rate for the lowest income bracket equal to zero as the effective average tax payments of this income class is effectively zero (Sieg (2000), does not provide an estimate for the lowest income class).

\subsection{Production}

The production elasticity of capital, $\alpha=0.36$, and the annual rate of capital depreciation, $\delta=0.04$, are taken from Heer and Linnemann (1998).

\subsection{Government expenditures}

Government consumption $G$ is calibrated in order to imply a government consumption share in output $G / F(K, N)$ equal to $19.6 \%$. ${ }^{9}$ Unemployment compensation $b$ is set equal to $52 \%$ of the average wage of the lowest productivity workers, $\epsilon^{2} \bar{n}^{2} w$, net of income taxes. This replacement ratio is computed using data from the GSOEP in 1995. In particular, we computed the replacement ratio with the help of the average net hourly income of the lowest quartile, ${ }^{10}$ the average monthly unemployment compensation (both unemployment insurance and unemployment assistance payments) and the median of the annual working hours.

\footnotetext{
${ }^{8}$ We would like to thank Holger Sieg for sending us the data.

${ }^{9}$ This value is taken from the monthly report of the Deutsche Bundesbank.

${ }^{10}$ We excluded all workers with an annual income of less than $1000 \mathrm{DM}$ or less than 250 yearly working hours from our computation.
} 


\section{Results}

In this section, the quantitative effects of a tax reform on employment, savings, distribution, and welfare are studied. First, equilibrium properties of the benchmark case with a progressive income tax are presented. In the following two subsections, the two tax reform proposals, the flat-rate income tax and the increase of consumption taxation, are considered in turn.

\subsection{Equilibrium properties}

In this subsection, we study the properties of the benchmark equilibrium which is characterized by the parameterization as presented in Table 1 . The household maximizes utility by the choice of labor supply and consumption. The policy functions depend on wealth $k$ and productivity $\epsilon$ and behave as expected. Optimal consumption of the employed worker increases with both productivity and wealth. In addition, wealth-poor agents with low productivity, $\epsilon<\epsilon^{3}$, are liquidity-constrained. Labor supply is an increasing function of productivity as the substitution effect is stronger than the income effect. Furthermore, labor supply is a decreasing function of wealth as the marginal utility of income declines with higher wealth.

The wage rate of each worker is simply his productivity $\epsilon^{i}$ times the aggregate wage level $w$. The net effect of productivity heterogeneity on the distribution of gross labor income, $n \epsilon w$, relative to the distribution of wage income, $w \epsilon$, is not straightforward in our model. On the one hand, high-productivity agents supply more labor for given wealth. On the other hand, the high-productivity agents are also richer than the low-productivity agents on average, which tends to reduce the supply of average working hours of high-productivity agents. For our calibration, we find that gross labor income is more unequally distributed than the wage rate. In fact, the Gini coefficient of gross labor income (wage rate) is equal to $0.309(0.254)$ and compares favorably with the empirical Gini coefficient which amounts to $0.317^{11}(0.2748)$. The Lorenz curve of the labor income distribution (broken line) is graphed in Fig. 1 and compared with the empirical distribution (solid line). In our model, labor income is a little less concentrated than observed empirically as the very productive agents receive a smaller labor income share and the least productive agents receive a higher labor income share. The difference is rather small as can be seen from the comparison of the Gini coefficients of the theoretical and the empirical distribution of gross labor income.

In equilibrium, the unemployment rate is equal to $10.95 \%$ (compare Table 3). Aggregate effective labor supply amounts to $N=0.245$ with an average working time approximately equal to $\bar{n}=0.320$. Working hours vary less than effective labor. The variational coefficient of working hours (effective labor) is equal to 0.363

\footnotetext{
${ }^{11}$ We computed the empirical Gini coefficient of gross wage income using the GSOEP data on annual individual labor income. For the computation, we deleted individuals with implausibly low or high implied hourly wage rates. We chose $7 \mathrm{DM}$ as the lower limit and $200 \mathrm{DM}$ as the upper limit. The number of deletions is small (about $0.17 \%$ at the top and about $6.5 \%$ at the bottom of the distribution).
} 


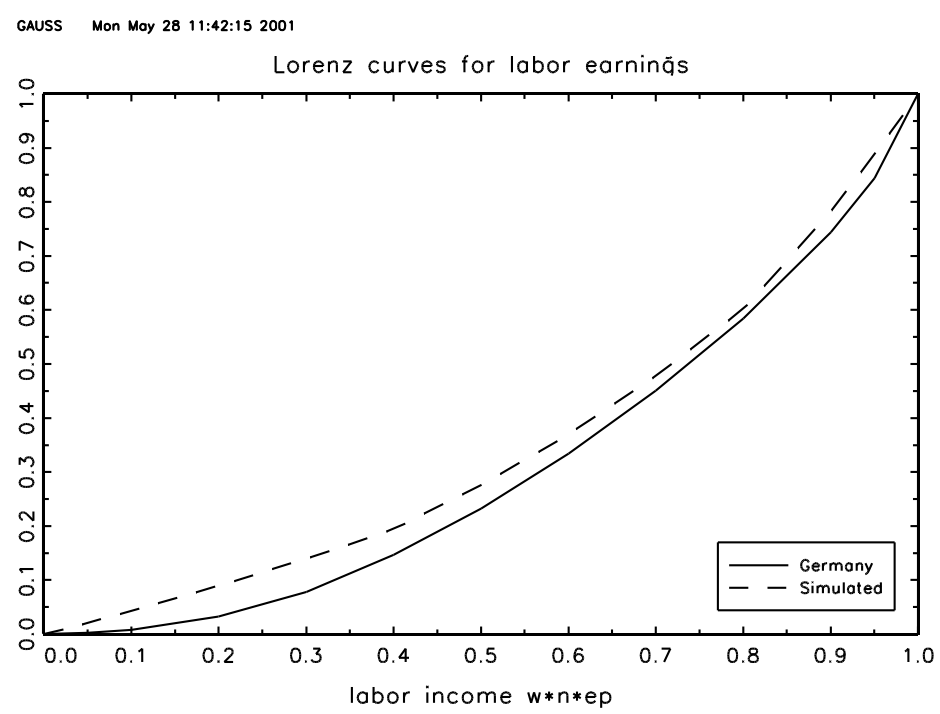

Fig. 1. Lorenz curve of gross labor income.

Table 3

Statistics of the benchmark case

\begin{tabular}{|c|c|c|c|c|c|c|c|c|}
\hline & \multirow[t]{2}{*}{$K / Y$} & \multirow{2}{*}{$\begin{array}{l}\text { Unem- } \\
\text { ployment } \\
\text { rate }(\%)\end{array}$} & \multicolumn{3}{|l|}{ GINI } & \multirow[t]{2}{*}{$\eta_{n, w}$} & \multirow[t]{2}{*}{$\sigma_{n} / \bar{n}$} & \multirow[t]{2}{*}{$\sigma_{\epsilon n} / \Lambda$} \\
\hline & & & Wage $w$ & $w \in n$ & Wealth $k$ & & & \\
\hline Benchmark case & 4.32 & 10.95 & 0.254 & 0.309 & 0.381 & 0.213 & 0.363 & 0.673 \\
\hline Empirical value & $2.6-5.0$ & 10.95 & 0.275 & 0.317 & $0.59-0.89$ & $0-0.2$ & 0.385 & 0.638 \\
\hline
\end{tabular}

(0.673) (see the last two columns of Table 3) and corresponds closely to empirical estimates using data from the German Social-Economic Panel during 1995-1996. Again, this reflects the optimization behavior of the working agents who work longer if they are more productive. The labor supply elasticity with regard to the wage rate, $\eta_{n w}$, is moderate, amounting to 0.213 for the average worker. Again, this compares favorably with the data. Sieg (2000) estimates that elasticities for male labor supply are small and in the range between 0.02 and 0.2 .

The aggregate capital stock amounts to $K=2.40$ which is associated with a capital-output coefficient equal to $K / Y=4.32$. During 1991-1997, the empirical value of $K / Y$ was equal to 5.0 (2.6) in Germany for the total economy (producing sector). The distribution of wealth, however, is not modelled in a satisfactory manner. In our model, the concentration of wealth is too low with a Gini coefficient equal to $\mathrm{GINI}_{\text {wealth }}=0.381$. Empirically, wealth is distributed much more unequally and characterized by a Gini coefficient in the range $0.59-0.89 .{ }^{12}$ The most important rea-

\footnotetext{
${ }^{12}$ Bomsdorf (1989) analyzes Gini coefficients of the wealth distribution for different kinds of assets in the periods 1973, 1978, and 1983 for West Germany. Within each asset group, Gini coefficients are remarkably stable. The distribution of savings, securities, and real estate in 1983 are characterized by Gini coefficients equal to $0.59,0.89$, and 0.74 , respectively.
} 
Table 4

Effects of tax policy reforms

\begin{tabular}{|c|c|c|c|c|c|c|c|c|c|c|}
\hline \multirow[t]{2}{*}{ Tax policy } & \multirow[t]{2}{*}{$K$} & \multirow[t]{2}{*}{$N$} & \multirow[t]{2}{*}{$\bar{n}$} & \multirow{2}{*}{$\begin{array}{l}r \\
(\%)\end{array}$} & \multicolumn{2}{|l|}{ GINI } & \multirow[t]{2}{*}{$\sigma_{n} / \bar{n}$} & \multirow[t]{2}{*}{$\sigma_{\epsilon n} / N$} & \multirow[t]{2}{*}{$W$} & \multirow{2}{*}{$\begin{array}{l}\Delta_{\mathrm{c}} \\
(\%)\end{array}$} \\
\hline & & & & & $\overline{w \in n}$ & $k$ & & & & \\
\hline (i) Progressive & 2.40 & 0.245 & 0.320 & 4.37 & 0.309 & 0.381 & 0.363 & 0.673 & -92.4 & 0 \\
\hline (ii) Flat-rate & 2.76 & 0.251 & 0.324 & 3.74 & 0.317 & 0.416 & 0.367 & 0.691 & -89.9 & 3.61 \\
\hline $\begin{array}{l}\text { (iii) Tax on } \\
\text { consumption }\end{array}$ & 3.24 & 0.249 & 0.323 & 3.01 & 0.316 & 0.410 & 0.366 & 0.685 & -86.9 & 8.18 \\
\hline
\end{tabular}

sons why our model fails to replicate the empirical wealth concentration are the neglect of life-cycle savings and business ownership. ${ }^{13}$

\subsection{A flat-rate tax reform}

In our first tax experiment, we replace the progressive German income tax schedule with a flat-rate income tax structure. In order to keep the government expenditures and tax revenues constant, we have to set the income tax rate equal to $\tau_{y}=17.4 \%$. Moving from a progressive to a flat-rate income tax, workers change their behavior. As all agents face the same marginal income tax rate $\tau_{y}$, the labor supply of the high-productive (low-productive) workers increases (decreases) as the marginal tax rates become lower (higher). However, in addition to this substitution effect, high-productive (low productive) worker also earn higher (lower) income and reduce (increase) labor supply because of the wealth effect. The net effect on both average working hours and aggregate labor $N$ is positive. Average working hours increase only moderately from 0.320 to 0.324 . Aggregate effective labor $N$ increases by $2.4 \%$ from 0.245 to 0.251 (see the second row of Table 4 ). While the variational coefficient of working hours hardly changes at all, the variational coefficient of effective labor increases from 0.673 to 0.691 .

The change in the savings behavior of households is qualitatively similar to the one in the labor supply. Households characterized by high productivity and wealth increase their savings as they face a lower tax rate on interest income under a flat-rate tax policy regime, while the opposite holds for wealth-poor and low-productivity households. The net effect on savings is positive and the aggregate capital stock $K$ rises from 2.40 to 2.76 following a switch from tax policy (i) to policy (ii). The rise of the capital stock is much more pronounced than the increase of aggregate employment so that the interest rate $r$ falls from $4.37 \%$ to $3.74 \%$.

\footnotetext{
${ }^{13}$ Quadrini and Ríos-Rull (1997) present a review of recent studies of wealth heterogeneity in computable general equilibrium models with uninsurable idiosyncratic exogenous shocks to earnings, including business ownership, higher rates of return on high asset levels, and changes in health and marital status, among others. A more ad hoc approach is provided by Krussell and Smith (1998) who simply introduce preference heterogeneity in the stochastic Ramsey model. In particular, they assume that the discount factor $\beta$ can take three different values and follows a Markov process with average duration of 50 years at the highest and lowest value of $\beta$.
} 
The change associated with the switch in tax policy in both the income and the wealth distribution is rather modest. The distribution of gross labor income of the employed workers $\left(\epsilon \geqslant \epsilon^{2}\right)$ as measured by the gini coefficient GINI $_{w \epsilon n}$ increases by 1 percentage points only as the low-productivity workers reduce their labor supply compared to the one of the high-productivity workers. ${ }^{14}$ Notice that the non-interest income of the unemployed workers even remains unchanged as unemployment benefits $b$ are kept constant. ${ }^{15}$ The distribution of wealth becomes more concentrated, too, and the wealth gini coefficient $\mathrm{GINI}_{k}$ rises from 0.381 to 0.416 . The more marked rise in the wealth gini compared to the one of the labor income gini simply reflects the relative increases of savings and labor supply.

In order to compare the welfare effects of the different tax systems, we need to specify a welfare measure. In the following, welfare $W$ is measured by the average life-time utility in the economy (please see Appendix A for the notation)

$$
W(\Omega)=\int_{\mathscr{X}} V(\epsilon, k ; \Omega) \mathrm{d} \psi(\Omega),
$$

where $\Omega$ denotes the tax policy. Note that the measure $\psi$ also depends on $\Omega$ since it describes the distribution of both state variables $k$ and $\epsilon$. The welfare effect of a change in the tax policy from $\Omega$ to $\Omega^{\prime}$ is measured by the consumption equivalent increase $\Delta_{\mathrm{c}}$ as suggested by McGrattan (1994). For our choice of the utility function, $\Delta_{\mathrm{c}}$ can be computed from

$$
1-\left(1+\Delta_{\mathrm{c}}\right)^{1-\sigma}=\frac{W\left(\Omega^{\prime}\right)-W(\Omega)}{\int_{\mathscr{X}} E_{0}\left[\sum_{t=0}^{\infty} \beta^{t} \frac{c_{t}^{1-\sigma}}{1-\sigma}\right] \mathrm{d} \psi(\Omega)},
$$

where expectations $E_{0}$ are taken conditional on expectations at the beginning of period 0 .

The change in welfare following a switch to the flat-rate income tax is pronounced. In fact, the welfare gain amounts to an increase of total consumption equal to $3.61 \%$. In the following, we consider the question how agents characterized by different wealth and productivity benefit from a change in the tax policy. We would expect the low-productivity poor agents to be the likely loosers from a switch to tax policy (ii). However, there are two opposing effects on the low-productivity workers' value: (1) The aggregate net wage rate decreases (even though the gross wage rises) and (2) expected utility in future periods rises. The second effect, of course, crucially depends on our realistic assumption that workers are mobile and may change their productivity between periods. In Fig. 2, the value functions of the low-productivity agent with $\epsilon^{2}=0.448$ are illustrated for the tax policies under consideration. For given wealth, life-time utility of all agents decreases as the progressive income tax rate is replaced by the flat-rate tax. ${ }^{16}$

\footnotetext{
${ }^{14}$ This result is in accordance with the result obtained by Castañeda et al. (1998) for the US economy.

${ }^{15}$ In our computation of the GINI ${ }_{w e n}$, we only accounted for the labor income of employed workers. The Gini coefficient of labor earnings, the latter defined as wage income plus unemployment benefits, is higher, both in our model and empirically (not presented).

${ }^{16}$ For productivities $\epsilon>\epsilon^{3}$, the value function for the tax policies (i) and (ii) cross each other for intermediate levels of wealth (not illustrated).
} 


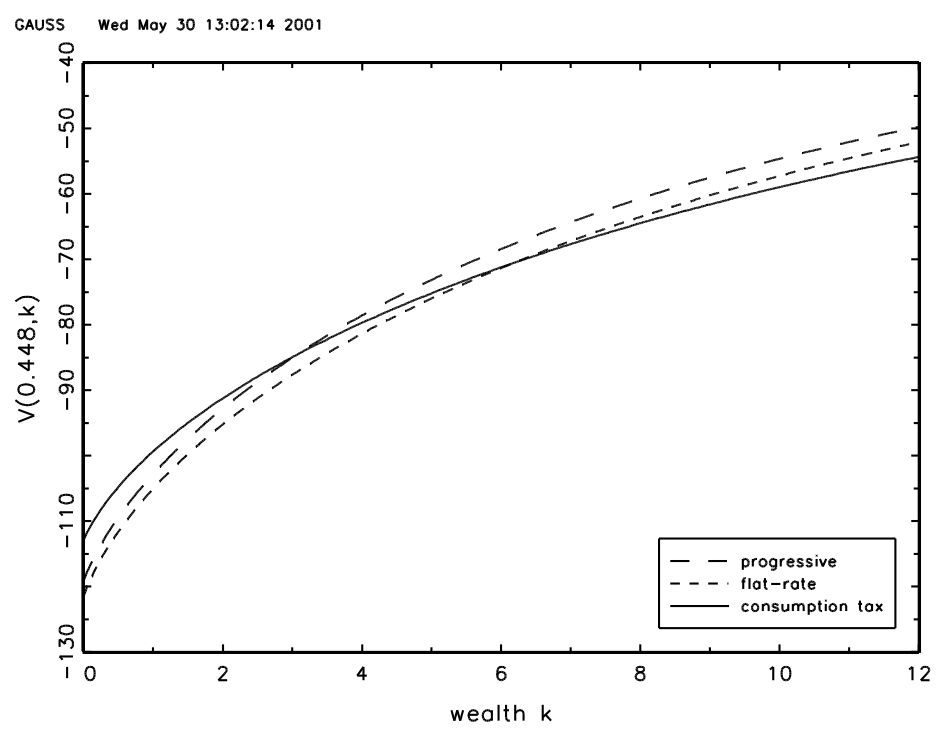

Fig. 2. Value function of the low-productivity employed worker.

The value functions illustrated in Fig. 2 are only an indicator that low-productivity workers loose from a flat-rate tax reform. However, following a change in the tax policy, the wealth distribution changes as well. As pointed out above, aggregate wealth increases while wealth also gets more concentrated. A meaningful welfare comparison, therefore, should analyze the different percentiles of the wealth distribution for each productivity type (due to our assumptions of constant transition probabilities, the measure of each productivity class remains the same under each tax regime). In Figs. 3 and 4, we graph the value of each percentile of the wealth distribution for the low and the high productivity type, $\epsilon=\epsilon^{2}$ and $\epsilon=\epsilon^{5}$, respectively. Obviously, the poorest two quintiles of the wealth distribution for the low-productivity

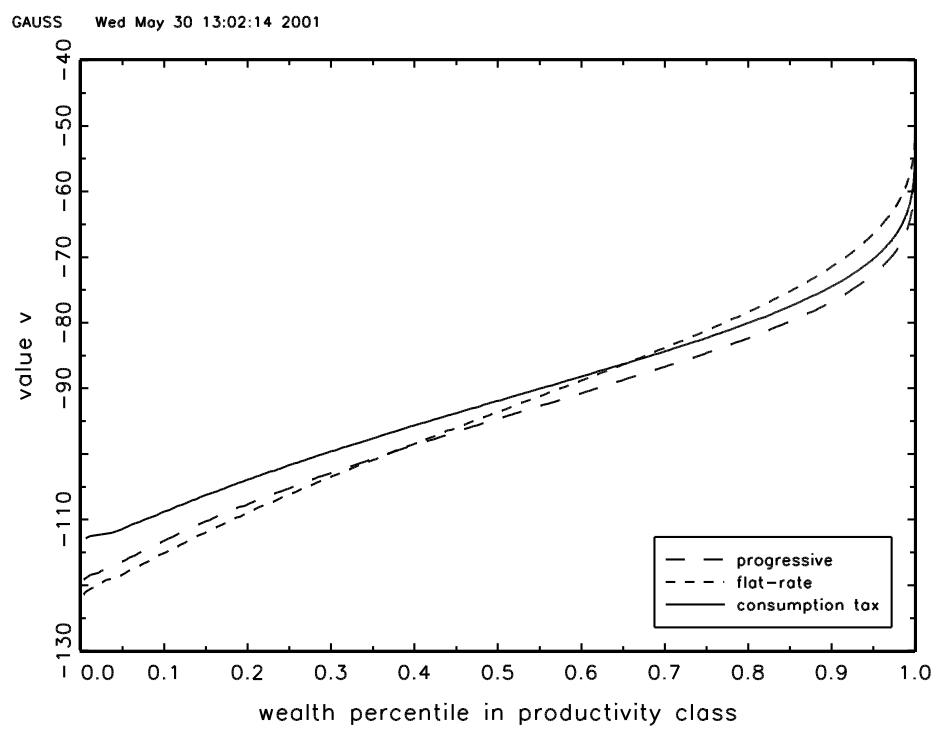

Fig. 3. Welfare decomposition for low-productivity workers. 


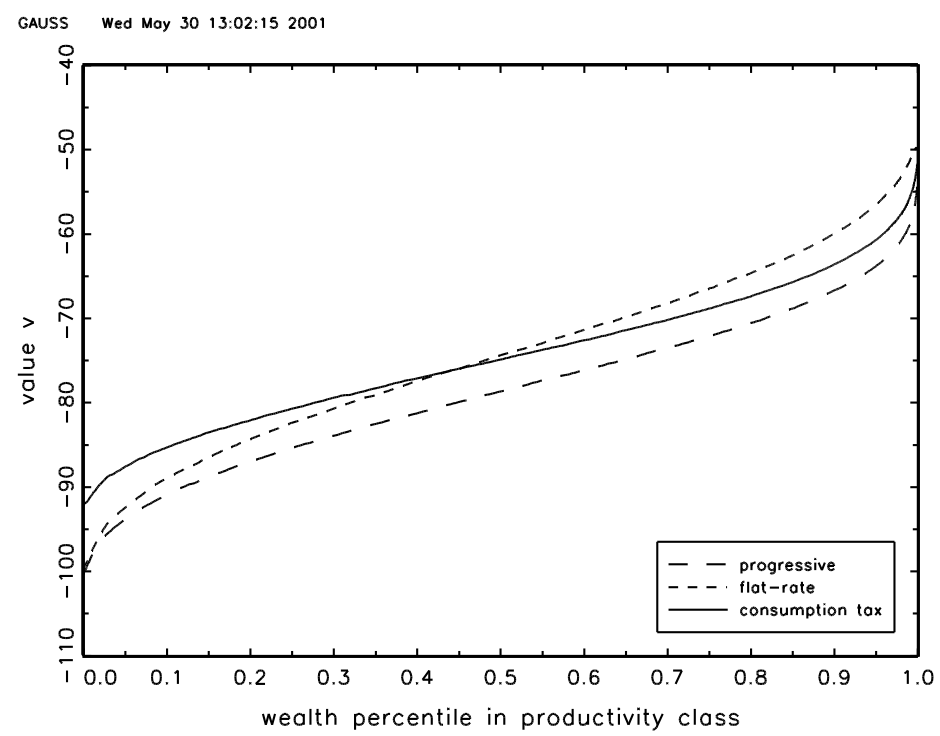

Fig. 4. Welfare decomposition for high-productivity workers.

agents is less well-off under a flat-rate tax regime. For the high-productivity workers, $\epsilon=\epsilon^{5}$, instead, every percentile of the wealth distribution benefits from a switch to a flat-rate tax.

At this point, one word of caution is warranted. We would be rather careful to draw firm policy implications from our welfare analysis because we only considered steady-state behavior of our economy. The neglect of transitional dynamics following a change in tax policy can have significant effects on welfare results. For example, Lucas (1990) analyzes the abolition of capital income taxes in an endogenous growth model with human capital accumulation. In steady state, the change in welfare amounts to a 3\% consumption equivalent gain. As demonstrated by Grüner and Heer (2000), also considering the transition from the old to the new steady state reduces the welfare gain of such a policy to $1 \%$ of total consumption. We carefully conjecture that switching from tax policy (i) to tax policy (ii) also implies welfare losses during the initial phase of transition. In the new steady state, average employment and average consumption are higher. Labor supply $n$ is a jump variable and adjusts instantaneously after a change in policy. Therefore, disutility from labor increases during transition. The capital stock is a sluggish variable and builds up slowly. Agents save a higher proportion of their income and consumption is lower during transition than in the new steady state and so is utility from consumption. As a result, instantaneous utility during transition is likely to be below the one in the new steady state on average. 17

\subsection{Consumption tax}

In our second tax experiment, we set the income tax rate to zero and increase the consumption tax rate in order to generate the same tax revenues as in the benchmark

\footnotetext{
17 The same comment applies to the consumption tax policy experiment in the next section.
} 
case. The new steady-state consumption tax amounts to $\tau_{\mathrm{c}}=39.5 \%$ (compared to $17.0 \%$ in the benchmark case). As interest income is not taxed any more, households increase their savings. Accordingly, the aggregate capital stock $K$ rises from 2.40 in the benchmark case to 3.24. As labor is not taxed any more, labor supply increases, even though to a much smaller extent than the capital stock, and aggregate employment goes up by $1.6 \%$. Associated with these changes of the input factors is a decline of the interest rate $r$ by almost $1.4 \%$ points.

The distribution effect of the tax reform, again, is rather modest and even smaller than in the case of the flat-rate tax reform. The Gini coefficient of gross labor income increases to 0.316 , merely by $2.2 \%$ above the benchmark case with progressive income taxation. Wealth, however, gets more concentrated and the Gini coefficient $\mathrm{GINI}_{k}$ even increases by $7.6 \%$. As the tax on interest income is abolished, wealth-rich and high-productive workers increase their savings by a higher proportion than wealth-poor workers. Low-productivity workers are liquidity-constrained over an increased range of low wealth compared to the benchmark case (not illustrated).

Again, the policy reform leads to substantial welfare gains in steady state. The welfare change is equivalent to a total rise of consumption equal to $8.2 \%$. As can be seen from Figs. 3 and 4, all employed workers benefit from a consumption tax. Only unemployed workers loose as their unemployment benefits are kept constant and can buy less consumption with higher consumption taxes (not illustrated).

\section{Conclusion}

This paper studies the general equilibrium effects of a flat-rate tax and a consumption tax reform for Germany. We develop a model that accounts for observed labor income mobility and distribution. Both reform proposals improve both efficiency and welfare compared to the allocation under the present German tax structure with a progressive income tax. Employment rises by approximately $2 \%$ under each proposed alternative tax regime, while savings even increase by $15 \%$ and $35 \%$ for the flat-rate tax and consumption tax regime, respectively. Welfare gains in steady state are substantial and amount to several percentage of total consumption for both reform proposals. While the distribution of gross labor income is hardly affected, the distribution of wealth changes significantly and becomes more concentrated.

We would like to reiterate that our results should be interpreted carefully. First, we have not computed the welfare losses which are likely to arise during transition after the tax policy switch to the new steady state. Second, we only studied labor adjustment along the intensive margin. The addition of non-competitive labor markets, e.g. in the form of search unemployment or union bargaining, which allow for the simultaneous study of labor adjustment along both the intensive and extensive margin is likely to have a profound effect on our results. Third, we assumed that the worker's productivity follows an exogenous stochastic process which is independent of the tax policy regime. In our view, the endogenization of productivity constitutes another promising extension of our model, in addition to the consideration of nonWalrasian labor markets. Productivity of the households, for example, could depend 
on the households' expenditures on education like in the model of Heckman et al. (1998) who explain rising US wage inequality in a heterogeneous-agent economy as a consequence of skill-biased technological change. As the tax policy regime is likely to affect individuals' expenditures on education and (on-the-job) skill formation, the distribution of productivity would be determined endogenously in such an extended model.

\section{Appendix A}

\section{A.1. Stationary equilibrium}

The concept of equilibrium used in this paper uses a recursive representation of the consumer's problem following Stokey et al. (1989). In the following, we concentrate on the study of a stationary equilibrium and drop time subscripts. The household's state variable is denoted by $x=(\epsilon, k) \in \mathscr{X}$. Let $V(\epsilon, k)$ be the value of the objective function of a household characterized by productivity $\epsilon$ and wealth $k$. $V(\epsilon, k)$ for the benchmark tax policy is defined as the solution to the dynamic program:

$$
V(\epsilon, k)=\max _{c, n, k^{\prime}}\left[u(c, 1-n)+\beta E\left\{V\left(\epsilon^{\prime}, k^{\prime}\right)\right\}\right],
$$

where $\epsilon^{\prime}$ and $k^{\prime}$ denote next periods productivity and wealth, subject to the budget constraint (4), the tax policy (9) and the stochastic mechanism determining the productivity level (1).

Let $(\mathscr{X}, \mathscr{B}, \psi)$ be a probability space where $\mathscr{B}$ is a suitable $\sigma$-algebra on $\mathscr{X}$ and $\psi$ a probability measure. We will define a stationary equilibrium for given government tax policy and stationary measure $\psi$.

\section{A.2. Definition}

A stationary equilibrium for a given set of government policy parameters is a value function $V(\epsilon, k)$, individual policy rules $c(\epsilon, k), n(\epsilon, k)$, and $k^{\prime}(\epsilon, k)$ for consumption, labor supply, and next-period capital, respectively, a time-invariant distribution of the state variable $x=(\epsilon, k) \in \mathscr{X}$, time-invariant relative prices of labor and capital $\{w, r\}$, and a vector of aggregates $K, N, B$ such that:

1. Factor inputs, consumption, tax revenues, and unemployment compensation are obtained aggregating over households:

$$
\begin{aligned}
& K=\int_{\mathscr{X}} k \mathrm{~d} \psi, \\
& N=\int_{\mathscr{X}} \epsilon n(\epsilon, k) \mathrm{d} \psi,
\end{aligned}
$$




$$
\begin{aligned}
& C=\int_{\mathscr{X}} c(\epsilon, k) \mathrm{d} \psi, \\
& T=\int_{\mathscr{X}} \tau(y(\epsilon, k)) \mathrm{d} \psi+\tau_{\mathrm{c}} C, \\
& B=\int_{\mathscr{X}} 1_{\epsilon=0} b \mathrm{~d} \psi .
\end{aligned}
$$

2. $c(\epsilon, k), n(\epsilon, k)$, and $k^{\prime}(\epsilon, k)$ are optimal decision rules and solve the household decision problem described in (A.1).

3. Factor prices (7) and (8) are equal to the factors' marginal productivities, respectively.

4. The goods market clears:

$$
F(K, L)+(1-\delta) K=C+K^{\prime}+G=C+K+G .
$$

5. The government budget (11) is balanced.

6. The measure of households is stationary:

$$
\psi(B)=\int_{\mathscr{X}} 1_{\left(\epsilon^{\prime}, k^{\prime}(\epsilon, k)\right) \in B} \pi\left(\epsilon^{\prime} \mid \epsilon\right) \mathrm{d} \psi
$$

for all $B \in \mathscr{B}$.

Since the household's decision problem is a finite-state, discounted dynamic program, an optimal stationary Markov solution to this problem always exists.

\section{Appendix B}

\section{B.1. Computational method}

The model has no analytical solution. Algorithms to solve heterogeneous-agent models with an endogenous distribution have only recently been introduced into the economic literature. Notable studies in this area are Aiyagari (1994, 1995), den Haan (1996), Huggett (1993), Imrohoroğlu et al. (1995), and Krussell and Smith (1998). Like most of these studies, we will only focus on the steady state of the model. ${ }^{18}$ The solution algorithm for the benchmark case with progressive income taxation is described by the following steps:

\footnotetext{
${ }^{18}$ den Haan (1996) and Krussell and Smith (1998) also compute the transition function of the capital stock distribution. For this reason, den Haan uses a specific class of function for the cross-sectional distribution of assets. Choosing the exponential family, he is able to characterize the distribution by a finite number of parameters. This procedure allows him to model the transition function of the distribution with a dynamic equation in a few parameters. Similarly, Krussell and Smith (1998) characterize the distribution by a finite number of moments. In the present analysis, however, the distribution is calculated without any assumptions on its functional form.
} 
1. Make initial guesses of the aggregate capital stock $K$, aggregate employment $N$, mean income $\bar{y}$, the consumption tax $\tau_{\mathrm{c}}$, and the value function $V(\epsilon, k)$.

2. Compute the wage rate $w$, the interest rate $r$, and unemployment compensation $b$.

3. Compute the household's decision functions by value function iteration.

4. Compute the steady-state distribution of assets, labor supply, labor income, and household income. ${ }^{19}$

5. Compute $K, N, \bar{y}$, and taxes $T$ that solve the aggregate consistency conditions.

6. Compute the consumption tax $\tau_{\mathrm{c}}$ that solves the government budget.

7. Update $K, N, \bar{y}$, and $\tau_{\mathrm{c}}$, and return to step 2 if necessary.

In step 3, the optimization problem of the household is solved with value function iteration. For this reason, the value function is discretized using an equispaced grid of 1000 points on the interval $\left[0, k^{\max }\right]$. The upper bound on capital $k^{\max }=12$ is found to never be binding. The asset decision is first obtained by bracketing the maximum over the asset grid by iterating over the grid. We then apply the Golden Search method ${ }^{20}$ to solve for the optimal next-period capital stock. As the optimal nextperiod capital stock may not be a grid point, we interpolate linearly between the neighboring points of the discretized value function.

Each time, the optimal labor supply has to be computed. In the case of a progressive income tax, the utility function is not differentiable everywhere with respect to labor hours. For tax regime (i), we proceeded as follows. We computed the marginal tax rate $\tau_{j}$ if the individual does not supply labor, $n=0$. If $\left(u_{1-n}(c, 1-\kappa)\right) /$ $\left(u_{c}(c, 1-\kappa)\right)<\left(u_{1-n}(c, 1)\right) /\left(u_{c}(c, 1)\right)$, where $u_{x}$ denotes the first derivative of the utility function with respect to the argument $x=c, 1-n$ and with $\kappa=0.001$ being a small constant, the optimal labor supply is set equal to zero. Otherwise, we computed the optimal labor supply for the tax rate $\tau_{j}$ from the condition

$$
\frac{u_{1-n}(c, 1-n)}{u_{c}(c, 1-n)}=\left(1-\tau_{j}\right) \epsilon^{i} w \text {. }
$$

If the income lies in the open interval $\left(Y_{j-1}, Y_{j}\right)$, we have found the optimal solution. If the implied income is larger than $Y_{j}$, we set the marginal income tax rate to $\tau_{j+1}$ and compute the optimal labor supply for the new tax rate. If the optimal income associated with $\tau_{j+1}$ lies in the interval $\left(Y_{j-1}, Y_{j}\right]$, the optimal labor supply is given by $n=\left(Y_{j}-r k\right) /\left(1-\tau_{j}\right) \epsilon^{i} w$ and the solution for the optimal labor supply corresponds to the non-differentiable point.

\section{Appendix C}

\section{C.1. Sensitivity analysis}

The intertemporal elasticity of substitution is controversial. Empirical estimates vary considerably. Hansen and Singleton (1983) and Mankiw et al. (1985) estimate

\footnotetext{
${ }^{19}$ Our numerical method for the computation of the stationary distribution follows Huggett (1993).

${ }^{20}$ For a description of the algorithm, see Press et al. (1992).
} 
Table 5

Sensitivity analysis of $\sigma$

\begin{tabular}{|c|c|c|c|c|c|c|c|c|c|c|}
\hline \multirow[t]{2}{*}{$\sigma$} & \multirow[t]{2}{*}{ Tax policy } & \multirow[t]{2}{*}{$K$} & \multirow[t]{2}{*}{$N$} & \multirow[t]{2}{*}{$\bar{n}$} & \multirow[t]{2}{*}{$r(\%)$} & \multicolumn{2}{|l|}{ GINI } & \multirow[t]{2}{*}{$\sigma_{n} / \bar{n}$} & \multirow[t]{2}{*}{$\overline{\sigma_{\epsilon n} / N}$} & \multirow{2}{*}{$\begin{array}{l}\Delta_{\mathrm{c}} \\
(\%)\end{array}$} \\
\hline & & & & & & $\overline{w \in n}$ & $k$ & & & \\
\hline 1 & (i) Prog & 1.77 & 0.202 & 0.256 & 4.91 & 0.326 & 0.399 & 0.366 & 0.705 & 0 \\
\hline 1 & (ii) Flat-rate & 2.07 & 0.206 & 0.263 & 4.2 & 0.336 & 0.445 & 0.372 & 0.744 & 1.98 \\
\hline 1 & (iii) Consumption tax & 2.41 & 0.212 & 0.265 & 3.43 & 0.334 & 0.452 & 0.371 & 0.740 & 6.02 \\
\hline 4 & (i) Progr & 356 & 0.309 & 0.402 & 3.54 & 0.297 & 0.344 & 0.363 & 0.632 & 0 \\
\hline 4 & (ii) Flat-rate & $4 .($ & 0.307 & 0.403 & 2.99 & 0.301 & 0.359 & 0.365 & 0.641 & 5.57 \\
\hline 4 & (iii) Consumption tax & 4.37 & 0.308 & 0.400 & 2.38 & 0.298 & 0.352 & 0.365 & 0.673 & 14.2 \\
\hline
\end{tabular}

a value of $\sigma$ close to unity, while Grossman and Shiller (1981) or Hall (1988) find an intertemporal elasticity of substitution $1 / \sigma$ between 0 and 0.4 . In simulation experiments based on the Ramsey model, we typically observe values in the range $\sigma \in[1,4]$, sometimes even values in excess of $\sigma=4$. For example, real business cycle analyses apply values of unity, $\sigma=1$, e.g. Kydland and Prescott (1982) or Hansen (1985); while Jones et al. (1993) use values $\sigma \in\{1,2,2.5\}$ for their calibration of an endogenous growth model. In this appendix, we analyze the sensitivity of our results in Section 4 with regard to the choice of $\sigma$. In Table 5, the simulation result for the model of Section 2 are summarized for the case of $\sigma \in\{1,4\}$. All other parameters are chosen as in Table 1.

Obviously, as agents become more risk averse (increasing $\sigma$ ), they increase precautionary savings and the aggregate capital stock $K$ rises. In fact, the rise in the capital stock is quite marked and aggregate capital stock is twice as high in the case of $\sigma=4$ compared to the case of logarithmic utility $\sigma=1$. In addition, wealth is less concentrated for higher risk aversion as low-income agents increase their savings in a higher proportion than high-income agents (see Table 5). All the qualitative effects of a flatrate tax reform are the same for $\sigma \in\{1,2,4\}$. In particular, both reform proposals (i) have only negligible effects on the labor income distribution, (ii) result in a moderate change of aggregate employment and a strong increase of aggregate savings, and (iii) imply significant steady-state welfare gains. The welfare gains are found to increase with the coefficient of risk aversion $\sigma$.

\section{Appendix D}

\section{D.1. Variable definitions}

$\epsilon \in \mathscr{E} \quad$ productivity

$\epsilon^{\prime} \quad$ next-period productivity

$\pi\left(\epsilon^{\prime} \mid \epsilon\right) \quad$ conditional transition probability from $\epsilon$ to $\epsilon^{\prime}$

$u(\cdot, \cdot) \quad$ instantaneous utility 
$\beta \quad$ discount factor

$c_{t} \quad$ consumption in period $t$

$n_{t} \quad$ labor supply in period $t$

$1 / \sigma \quad$ intertemporal elasticity of substitution

$k \quad$ individual capital stock

$K \quad$ aggregate capital stock

$r \quad$ interest rate

$w \quad$ wage rate

$\tau_{\mathrm{c}} \quad$ consumption tax rate

$1_{\epsilon=0} \quad$ index function equal to one iff $\epsilon=0$, zero otherwise

$y_{t} \quad$ taxable income in period $t$

$\tau\left(y_{t}\right) \quad$ income taxes in period $t$

$\tau_{y} \quad$ flat income tax rate

$\tau_{i}, i=1, \ldots, M$ marginal income tax rates

$\left[Y_{i}, Y_{i+1}\right]$ income tax bracket

$F(\cdot, \cdot)$ production function

$N \quad$ aggregate effective labor

$\delta \quad$ depreciation rate of capital

$G \quad$ government consumption

$T \quad$ tax revenues

\section{References}

Aiyagari, S.R., 1994. Uninsured idiosyncratic risk and aggregate saving. Quarterly Journal of Economics 109 (3), 659-684.

Aiyagari, S.R., 1995. Optimal capital income taxation with incomplete markets, borrowing constraints and constant discounting. Journal of Political Economy 103 (6), 1158-1175.

Bomsdorf, E., 1989. Die personelle Vermögensverteilung in der Bundesrepublik Deutschland 1973, 1978 und 1983. Vierteljahreshefte zur Wirtschaftsforschung, Heft 4, 328-335.

Castañeda, A., Díaz-Giminénez, J., Ríos-Rull, J.-V., 1998. Earnings and wealth inequality and income taxation: Quantifying the trade-offs of switching to a proportional tax in the US. University of Pennsylvania, Mimeo.

den Haan, W.J., 1996. Understanding equilibrium models with a small and a large number of agents. NBER Working Paper no. 5792.

Grossman, S.J., Shiller, R.J., 1981. The determinants of the variability of stock market prices. American Economic Review 71 (2), 222-227.

Grüner, H.P., Heer, B., 2000. Optimal flat-rate taxes on capital—a reexamination of Lucas' supply side model. Oxford Economic Papers 52 (2), 289-305.

Hall, R.E., 1988. Intertemporal substitution in consumption. Journal of Political Economy 96 (2), 339 357.

Hansen, G.D., 1985. Indivisible labor and the business cycle. Journal of Monetary Economics 16 (3), 309327.

Hansen, L.P., Singleton, K.J., 1983. Stochastic consumption, risk aversion and the temporal behavior of asset returns. Journal of Political Economy 91 (2), 249-265.

Heckman, J.J., Lochner, L., Taber, C., 1998. Explaining rising wage inequality: Explorations with a dynamic general equilibrium model of labor earnings with heterogenous agents. Review of Economic Dynamics 1 (1), 1-58. 
Heer, B., 2003. Employment and welfare effects of a two-tier unemployment compensation system. International Tax and Public Finance, forthcoming.

Heer, B., Linnemann, L., 1998. Procyclical labor productivity: Sources and implications. Zeitschrift für Wirtschafts- und Sozialwissenschaften 118 (2), 221-247.

Huggett, M., 1993. The risk-free rate in heterogenous-agent incomplete-insurance economies. Journal of Economic Dynamics and Control 17 (5-6), 953-969.

İmrohoroğlu, A., İmrohoroğlu, S., Joines, D.H., 1995. A life cycle analysis of social security. Economic Theory 6 (1), 83-114.

Jones, L.E., Manuelli, R.E., Rossi, P.E., 1993. Optimal taxation in models of endogenous growth. Journal of Political Economy 101 (Fall), 485-517.

Krussell, P., Smith, A.A., 1998. Income and wealth heterogeneity in the macro-economy. Journal of Political Economy 106 (5), 867-896.

Kydland, F.E., Prescott, E.C., 1982. Time to build and aggregate fluctuations. Econometrica 50 (6), 13451370.

Lockwood, B., Manning, A., 1993. Wage setting and the tax system: Theory and evidence for the United Kingdom. Journal of Public Economics 52 (1), 1-29.

Lucas Jr., R.E., 1990. Supply-side economics: An analytical review. Oxford Economic Papers 42 (2), 293 316.

McGrattan, E.R., 1994. The macroeconomic effects of distortionary taxation. Journal of Monetary Economics 33 (3), 573-601.

Mankiw, N.G., Rotemberg, J.J., Summers, L.H., 1985. Intertemporal substitution in macroeconomics. Quarterly Journal of Economics 10 (1), 225-251.

Press, W.H., Teukolsky, S.A., Vetterling, W.T., Flannery, B.P., 1992. Numerical Recipes in FORTRANThe Art of Scientific Computing. Cambridge University Press, Cambridge.

Quadrini, V., Ríos-Rull, J.-V., 1997. Understanding the US distribution of wealth. Federal Reserve Bank of Minneapolis Quarterly Review 21 (2), 22-36.

Shorrocks, A.F., 1976. Income mobility and the Markov assumption. Economic Journal 86 (3), 566-578.

Sieg, H., 2000. Estimating a dynamic model of household choices in the presence of income taxation. International Economic Review 41 (3), 637-668.

Stokey, N., Lucas, R.E., Prescott, E.C., 1989. Recursive Methods in Economic Dynamics. Harvard University Press, Cambridge, MA.

Ventura, G., 1999. Flat-rate tax reform: A quantitative exploration. Journal of Economic Dynamics and Control 23 (9-10), 1425-1458. 